\title{
Consumer Behavior and Marketing Strategy of Apparel Luxury Goods on Chinese E-commerce Platform
}

\author{
Yuyang $\mathrm{Li}^{1, *}$ \\ ${ }^{1}$ Keystone Academy, Beijing, 101300, China. \\ * Corresponding author. Email: Yuyang.li.1@student.keystoneacademy.cn
}

\begin{abstract}
Since 2008, e-commerce marketing has become an important way to market luxury goods with the increase of online luxury consumption in China. E-commerce platform not only promotes economic development but also gradually becomes a way of life and consumption. The methods of this paper are literature analysis and summarization and induction. This paper has analyzed the current status of the Chinese E-commerce apparel luxury market and the problems and issues of the E-commerce platforms, mainly including product, price, and service issues. This paper summarized the social motivational behaviors of E-commerce apparel luxury consumers, including conformist, showing off and psychological comparison; and personal motives, including information gathering, convenience, selfactualization, and hedonism. Based on the existing problems and consumer motivations, this paper has suggested four marketing strategies: product strategies, pricing strategies, service strategies, and process strategies. This paper analyzes the current situation of apparel luxury E-Commerce platform, organizes the consumer motivation, and proposes the corresponding marketing strategy. It is a reference for luxury brands and luxury e-commerce enterprises to carry out better online marketing strategies, which has certain guiding significance and provides research materials for subsequent research.
\end{abstract}

Keywords: Chinese E-commerce Platform, Apparel luxury goods, Consumer Behavior, Marketing Strategy

\section{INTRODUCTION}

With the reduction of import tariffs, rapid development of technology and emergence of millennials (Born between 1980 and 1995, about 320 million people) and Generation Z (Born after 1995, of whom about 80 million) consumers, China has become one of the largest markets of luxury goods. In 2018, Chinese consumers' consumption of luxury goods reached 770 billion RMB, accounting for one-third of the total global consumption of luxury accessories [1]. By 2025, the total consumption of luxury accessories is expected to increase to 1.2 trillion RMB [1]. These increases have largely promoted the growth of the national economy and benefited the economic development of China. In E-commerce platforms, the online penetration of luxury sales in China grew from around $13 \%$ in 2019 to $23 \%$ in 2020 . Generation Z Consumers spend an average of five hours on mobile devices, which accounts for increasing consumers using E-commerce platforms as the main channel for purchasing luxury goods [2]. Nevertheless, E-commerce platforms have only emerged in recent years with the advancement of the Internet. Hence the marketing strategies of online platforms are still in an immature state. Without the right marketing strategy, the development of the apparel luxury goods market in China will be hindered. Therefore, it is necessary to analyze the consumer behavior of apparel luxury good consumers on Chinese E-commerce platforms and suggest pertinence marketing strategies to ensure the stable development of apparel luxury market in China and mature E-commerce platform marketing.

In The Wealth of Nations, Adam Smith defines consumer goods as necessities and luxuries, where necessities are those goods that people can use to support themselves to live, and those goods that are not necessities are luxuries [3]. For the not-necessities, consumers must have some extent of incentives or motivations for purchasing them. Those motivations can largely be categorized as social factors and personal 
factors [4]. In social factors, consumers buying luxury clothes have the intention to show off their wealth, achieve vanity and obtain a higher status. In personal factors, some consumers are hedonism who buys luxury goods as a way of self-enjoyment; others simply pursue high quality and unique design luxury clothes [4]. With the emerging of E-commerce platforms, consumers also value the efficiency and convenience it provides and the advantage of gathering more detailed information online. In the Chinese market, $47.3 \%$ of E-commerce consumers are traditional entry-level consumers who are influenced by a variety of motivations rather than a specific one [5]. According to those consumer motivations, Fei has provided the following marketing strategies. In terms of product strategy, enterprises should actively seek official brand authorization cooperation, provide overseas purchase services, and develop after-sales service products. Price strategy needs to implement price transparency, and use the high price strategy appropriately. In addition to actively building E-commerce word-of-mouth and TV advertising, the promotion strategy should also attract consumers with other new value-added services, such as small interest-free loans for consumers or second-hand luxury goods consignment [5]. Balasyan \& Casais also points out that "the key success factors of luxury Ecommerce are product range, qualified team, provided service and webpage" [6].

At the present stage, most scholars focused on the consumer behavior of luxury consumers and mainly analyzed the motivations that promote consumers to buy luxury products. In addition, many articles focused on the analysis of offline luxury stores as online platforms have only gradually appeared in recent years. Few papers have studied consumer behavior specifically in China's apparel luxury E-commerce platform and provided targeted marketing strategies.

This paper will use the method of literature analysis and summarization \& induction. First, this study will analyze luxury clothing brands' consumption status and sales status on China's E-commerce platforms. The two main E-commerce platforms which will be investigated are Taobao and JD. Next, this study will analyze consumer behavior characteristics of those apparel luxury brands consumers using Taobao and JD. This part is mainly divided into two sections which are social motivation and personal motivation. Finally, this study will optimize the existing marketing strategy and propose new marketing strategies according to the consumer behavior of China's apparel luxury Ecommerce platform.

\section{METHODOLOGY}

\subsection{Literature Analysis}

The literature analysis is a method of obtaining information based on a certain research purpose or the topic of investigation. This method helps to gain a comprehensive and accurate understanding of the problem to be studied. Its functions are to understand the history and current situation of the issue in question and to help determine the research topic. It can form a general impression about the research object and get comparative and realistic information [7]. In this paper, literature analysis might include reports and industry report data on the current state of the E-commerce apparel luxury market, such as the consumption and sales data. By using the literature analysis method, this study examines the current state of the apparel luxury Ecommerce market, whether the market is performing well or not, which is important as the first step of the research approach.

\subsection{Summarization \& induction}

Summarization and induction are a method of arguing from the individual to the general. It passes through many individual examples or sub-arguments and then summarizes the characteristics they share to reach a general conclusion [7]. This paper will summarize the consumer behaviors of apparel luxury Ecommerce consumers in China. There are various motivations for consumers to purchase apparel luxury, summarized into social and personal factors. This paper will also summarize the main characteristics of consumer behavior to develop and optimize marketing strategies accordingly.

\section{RESULTS}

\subsection{Chinese E-commerce apparel luxury market analysis}

\subsubsection{The status of Chinese E-commerce apparel luxury market}

Both the number and scales of apparel luxury market E-commerce platforms are enormous, with China's luxury e-commerce platform selling 57.36 billion yuan in 2016, up by $43.0 \%$ from 40.1 billion yuan in 2015 [8]. This boom cannot be overstated and will continue to grow rapidly in the future. The main platforms that apparel luxury consumers choose to use are Taobao, JD, Tmall Global and Du. The main consumers of those apparel luxury markets are millennials. Millennials spend an average of 17.5 hours per week on the Internet, and about 98 percent of millennials use social media [9]. Hence, many millennials users have largely contributed to the rise of apparel luxury E-commerce platform. 
Another notable point is that many Chinese e-commerce platforms sell more mainly foreign clothing brands, such as Louis Vuitton, Coach, Burberry, etc. However, in recent years, Chinese designer brands like Alexander Wang are gradually being recognized by the public.

\subsubsection{The challenges faced by apparel luxury E- commerce platform}

Despite the number and size of luxury E-commerce platforms in China are steadily increasing, many of the platforms still have significant and non-negligible problems.

\subsubsection{Product}

First, most of the luxury clothing sold on online platforms are the most popular and trendy styles, which can lead to problems such as lack of supply and out of stock. In this way, consumers will choose offline or other shopping channels, causing the lack of consumer base of the E-commerce platform.

Second, the supply source of some online platforms is unclear, and these platforms usually do not have official cooperation with luxury brands. Therefore, the authenticity of apparel luxury sold online is questioned by consumers, and this will become a very serious problem if the quality of the products is not guaranteed. "However, although most platforms are equipped with the slogans "100\% certified products" and "Ten times compensation

\subsubsection{Price}

In order to meet the needs of growing customers, some e-commerce platforms will use low-price strategies to attract consumers. This phenomenon is evident in many platforms. "For example, 80 percent of the luxury goods on ihaveu, Mei, Vip, Net-A-PORTER and Farfetchare under 10,000 yuan, with a small proportion higher than 15,000 yuan and more than 50,000 yuan [8]." While this marketing strategy does bring in considerable amounts of customer volume in the short term, it also leads to a tarnished image for platforms. If luxury e-commerce platforms continue to sell luxury clothing at lower prices, consumers will question the authenticity and quality of the products, and the public will distrust these platforms. Therefore, e-commerce platforms need to find a reasonable balance between discount and high price.

\subsubsection{Customer Service}

The customer service of the e-commerce platform has also become a major problem. Luxury goods

Brands are reluctant to provide after-sales service, and the website after-sales service is not perfect, especially the repair and maintenance of goods, which is an important factor that prevents consumers from buying [5]. "The service range of local comprehensive luxury e-commerce platforms such as SECOO, Mei is so wide that it is difficult to return consumers' expenses or exchange their unsatisfying goods [8]."

\subsection{Analysis of E-commerce apparel luxury consumers' behavior and characteristics in China}

The consumer behavior of E-commerce platform apparel luxury brand consumers mainly originates from consumers' purchase intentions. This paper will mainly analyze the two major types of motivations, namely social and personal motives.

\subsubsection{Social Motives}

"Social values and norms of social institutional rules that arose from the side of family and other reference groups put pressure on consumer luxury purchase intention" [10].

\subsubsection{Showing off}

Under the category of social motivation, the most common motivation is showing off. Consumers in this category purchase luxury apparel to show their wealth and status, intending to obtain social recognition from their surrounding people. Generally, show off consumers pay less attention to the brand culture of the apparel luxury, but value more how the public recognizes the brand. Among the overall E-commerce apparel luxury consumers, this group accounts for $22.3 \%$, most of which are students and male consumers with immature consumption concepts [5].

\subsubsection{Conformist}

The second type of consumer is conformist, who follows the trend and conforms to bandwagon to pursue the most popular and latest luxury clothing. When buying luxury products, they will consider whether the products are popular, conform to the trend and especially the aesthetic trend, because their main purpose is to follow the trend. Therefore, E-commerce platforms are considerably useful for conformists' consumers to search for the most popular apparel luxury products online.

\subsubsection{Psychological comparisons}

The third type of social factor-driven consumers are those who often compare themselves to others. They are largely influenced by their surrounding people, friends, and family. When others purchase apparel luxury products, consumers who try to be preeminent would 
also purchase similar apparel luxury products to gratify their own vanity. For these consumers, purchasing apparel luxury products seems to be a competition, and they have a strong desire to excel others. They value brand recognition over brand culture since they want to purchase the most luxury and valuable brands to win the potential competition.

\subsubsection{Personal Motives}

"Excellent quality, unique design are the most important factors that personal driven consumers value when choosing luxury good" [11]. They do not need to use the brand to show off and do not want to have too much contact with the staff in the store. Luxury for them is a way of life, reflecting the lifestyles and tastes. They believe that expensive luxury goods guarantee high quality, good design and workmanship.

\subsubsection{Convenience}

Under the category of personal motivation, convenience is a strong incentive prompting people to consume on E-commerce platforms. Some consumers avoid contact with store sales, so online shopping is more convenient and suitable for them. In addition, ecommerce provides consumers with a more efficient and convenient consumption experience. Consumers only need to spend the minimum amount of time on the website to search for the goods they want, instead of spending a long time in the physical store to choose the appropriate luxury clothing. Consumers who live in remote areas also choose to buy appeal luxury goods via E-commerce platforms, or in times of special periods like pandemics, people often choose to use E-commerce platforms to purchase luxury apparel. Although online shopping sometimes faces the problem of consumer. Purchasing inappropriate clothing size, most consumers think that the return and exchange process is still very convenient.

\subsubsection{Information gathering}

The advantage of information brought by ecommerce platform to consumers is also not to be underestimated. It is noticeable that consumers involve in purchasing luxury brands are more conscious about product \& make highly [4]. Therefore, consumers will use access to a large amount of commodity information on the network platform and compare many commodities. Consumers can also see other customers' comments, further evaluating the product. However, in physical stores, sales do not provide comprehensive and true information about the products, taking longer. Therefore, the large amount of information and various choices on the e-commerce platform are powerful motives

\subsubsection{Self-actualization and hedonism}

Consumers who care less about vanity and status purchase luxury apparel only for self-actualization and hedonism. This type of consumers usually is prosperous and wealthy, they have purchased luxury brands for a long time. They value the cultural background and quality of the apparel luxury that the brands offer. These consumers consume luxury goods to satisfy their own aesthetic and emotional needs, and most of them will buy luxury goods to reward themselves for commemorating certain moments that have special significance to them. As they have rich knowledge of luxury goods, they are bolder in purchasing products and are willing to try niche or luxury brands that have not yet entered China. When choosing products, they are not concerned with the price and brand recognition, but the quality and unique design [11].

Consumers are still not motivated by a single factor to purchase luxury apparel, but rather are motivated by multiple motivations to spend. These individuals represent $47.3 \%$ of the overall consumer [5].

\section{DISCUSSION: CHINESE E-COMMERCE APPAREL LUXURY MARKETING STRATEGY AND OPTIMIZATION}

\subsection{Product Strategy}

\subsubsection{Improve product quality}

The core of marketing strategy is the product itself; it is what the customer values the most. For apparel luxury e-commerce platforms, it is necessary for the platform and the merchant to guarantee the quality of the clothing. Their guarantees to the product quality will be more responsible than offline stores because consumers are not able to physically see and touch the goods, not to mention evaluating the quality of clothes. Besides, apparel luxury is expensive. Consumers don't want to bet on products that are not worth buying. Therefore, the e-commerce platform must ensure the high quality of clothing luxury, otherwise, consumers will not make a second purchase, and the platform will not build a strong customer base.

\subsubsection{Cooperate with brands officials}

A common problem in Chinese e-commerce platforms is counterfeit goods. Many consumers report that the products they receive do not match genuine luxury goods, mainly due to unreliable purchase channels. Hence, it is essential for e-commerce platforms to cooperate with brands officials. Some ecommerce platforms, such as Taobao and JD, already have official brand cooperation bases, such as Coach's official flagship store, Burberry's flagship store, etc. 
However, as more consumers choose to buy apparel luxury online, e-commerce platforms need to inject more official brand partnerships to ensure the quality of luxury goods, while enhancing the reputation of the platforms.

\subsubsection{Cooperate with reliable overseas Daigou channel}

In recent years, Daigou has become very popular. This is a new way of consumption, some merchants will go abroad to buy apparel luxury in bulk and bring it back to China to sell, which provides consumers with conveniences. However, Daigou is still in an immature stage, and some consumers have reported problems with fake products, low quality and high price. Therefore, ecommerce platforms can cooperate with reliable overseas Daigou to provide a more secure Daigou channel to consumers. On the other hand, many ecommerce platforms do not have access to foreign apparel luxury goods, and cooperation with Daigou will be a good opportunity to provide overseas goods to ecommerce platforms.

\subsection{Price Strategy}

\subsubsection{Increase price concessions}

E-commerce platforms can attract more customers with discounts, coupons, freebies, and other price concessions. Many stores will offer electronic coupons, which drives consumers to spend repeatedly. In addition, because consumers can compare the prices of products at a glance when shopping online, many consumers will choose a lower price when purchasing products. Besides, e-commerce platforms can choose to do promotions during holidays, such as Christmas and Chinese New Year, when more consumers will buy apparel luxury to wear.

\subsubsection{Implement price skimming}

While some consumers focus on cheap prices, some quality-conscious consumers will choose the opposite. For such consumers, the high price strategy is more applicable. When people see expensive luxury goods, they will naturally deduce that the quality of the goods is high and worth buying. Therefore, e-commerce platforms can selectively increase the price of some goods to attract quality-conscious consumers. And when more customers consume the item, the merchant can lower the price. This strategy is also called price skimming, in which a high price is set at the time of product launch, and then the price is gradually reduced as more competitors enter the market.

\subsection{Service Strategy}

\subsubsection{Optimize customer service}

Many e-commerce platform users are not satisfied with customer service. The attitude of some online salespersons is very poor, they are different from the sales of retail stores, because it is an online platform, so it is impossible to monitor the attitude of these employees in real time. This will greatly affect the consumer experience, and even consumers will complain or leave bad reviews, affecting the reputation of the e-commerce platform. Therefore, customer service is very important. The e-commerce platform must make sure that the salesperson is always online, ready to answer any questions from consumers, and possess a good attitude. In addition, there are many problems with the products during transportation. For example, express loss, express damage, slow receipt and other similar problems. Although e-commerce platforms mainly focus on selling goods, express delivery is also a very important step. Therefore, e-commerce platforms can cooperate with guaranteed courier companies to give consumers the most perfect purchase and transportation services.

\subsubsection{Improve after-sales service}

Customer service in the consumer purchase process is important, and after-sales service is even more important. The problem with e-commerce platform to buy clothing is that the size is not suitable, the style is not suitable, or the consumer is not satisfied with the physical product. Some consumers reflect that the clothes do not fit after receiving the goods, but the business did not make a reasonable solution, or do not allow consumers to return or exchange. Therefore, merchants need to inform consumers whether the apparel luxury can be returned after the consumer receives the goods. Most clothing stores are obliged to provide consumers with the right to return the product for seven days, and the e-commerce platform should handle the cost of the return.

\subsection{Process Strategy}

\subsubsection{Use big data and technology}

In the era of big data, e-commerce platforms can use technology to help consumers buy more efficiently and conveniently. E-commerce platforms can personalize each consumer based on their purchase history, browsing history and search history. Recommending the right products to them on the homepage saves time and makes consumers more dependent on the e-commerce platform. "In the early days of the luxury époque, Louis Vuitton hand wrote specific suggestions to a customer to recommend particular travel bags for a transatlantic journey to New York City. Today, big data and 
advanced analytics help brands find opportunities to provide services that are uniquely tailored to each customer and occasion, making the brands appear as authentic as Vuitton's notes" [9]. Therefore, ecommerce platforms can make good use of big data and technology to increase customer intimacy.

\subsubsection{3-D fitting customer service}

With the development of high technology, 3-D tryon has become popular. For example, a domestic sneaker platform "Du" has a special 3-D fitting customer service, where consumers only need to put their cell phones at their feet to see how the sneakers, and to evaluate the suitability of the product. For apparel luxury brands, this will be a very good opportunity to compensate for the missed opportunity that consumers cannot try on. More e-commerce platforms can use this technology to provide consumers with a reliable consumer experience, so that consumers will also have a greater chance of buying apparel luxury products.

\section{CONCLUSION}

\subsection{Summary main findings}

The paper focuses on the consumer behavior and marketing strategies of apparel luxury goods on Chinese E-commerce platform. Consumer motivation can be categorized into two types, which are social motives and personal motives. The majority of consumers do not possess a particular motive when purchasing luxury apparel, rather they are motivated by a mixed of motivations. Besides those consumers, many people purchase luxury apparel as a means of showing their wealth and status. While others simply pursue high quality and unique design clothing. Despite the booming usage of E-commerce as a purchase channel and the emergence of the Chinese luxury E-commerce platform, most apparel luxury E-commerce markets are still immature, with unavoidable issues such as low and fake quality products, unreasonable pricing strategies, and dissatisfied customer service. As a result, pertinence strategies must be implemented to solve urgent problems. E-commerce platforms can cooperate with brand officials to guarantee the quality and authenticity of the product for product strategies. For pricing strategies, E-commerce platforms should consider implementing the right strategies at the right time, for instance price skimming. Customer service can be improved by providing thorough before-sale and aftersale services, and even express service. Lastly, with the fast pace development of technology, platforms can attempt to use 3-D fitting service to stand out among the E-commerce platform and present their uniqueness.

\subsection{Limitation and prospect}

The main limitation of this paper is the lack of primary data, such as survey and interviews. The Survey can be sent to apparel luxury E-commerce platform users to investigate their experience with E-commerce platforms and satisfaction rate. This will provide reliable data to argue whether the E-commerce platforms are satisfying the consumer's need and what to improve in the future. Interviews to marketing professions can be conducted to testify the effectiveness of current marketing strategies of E-commerce platforms. Hence, future studies should engage more primary sources to support arguments. The reliability of secondary data is also questioned. Some of the articles are published by university students in China, who might possess a biased view of Chinese E-commerce platforms. The data of these articles might be inaccurate or imprecise, with errors and outliers.

Future research can also analyze the effectiveness of Chinese luxury E-commerce platforms' marketing strategies since nowadays, consumers' tastes and the development of technology are changing rapidly. Artificial intelligence and augmented reality can lead Ecommerce platforms to a promising future.

\section{REFERENCES}

[1] McKinsey's Apparel, Fashion \& Luxury consulting team in China, China Luxury Report 2019, McKinsey and Company, 2019, p.3-4.

[2] B. Lans, J. Zhang, China's luxury market in 2020: unstoppable, Bain Company, p.6-7.

[3] Adam Smith's Wealth of Nations: The Commercial Press, 1974.

[4] M. Abrar, M. Bashir, R. Shabbir, M. Haris, S. Saqib, Role of Personality and Social Factors towards Purchase of Luxury Clothing in Online Settings: Moderating Role of Vanity, European Online Journal of Natural and Social Sciences 2019, p.43-45.

[5] T. Fei, Research on the purchase motives and types of consumers of luxury clothing on online platforms, 2014, p.7-93.

[6] I. Balasyan, B. Casais, Keeping Exclusivity in An E-commerce Environment: The case of Farfetch.com and the market of luxury clothes, International Journal of Marketing, Communication and New Media, 2019, p.15-20.

[7] CNKI Academic Research, 20 common research methods used in dissertations, sciping.com, 2018, https://mp.weixin.qq.com/s/4JH6LGb3HHu8R9df ONSXpw. 
[8] J.Li, M.Zhang, The Future of China's Luxury Ecommerce Marketing, International Conference on E-commerce and Contemporary Economic Development , 2018, p.1-6.

[9] McKinsey's Apparel, Fashion \& Luxury Group, The age of digital Darwinism, McKinsey and Company, 2018, p.1-15.

[10] Shukla, P. (2012). The influence of value perceptions on luxury purchase intentions in developed and emerging markets. International Marketing Review, 29(6), 574-596.

[11] Y.Du, The changing mature consumer behavior of Chinese customer in luxury market, 2017, p.2-80. 